\title{
The Perspective Of The Cordilleran People On The Political, Economic And Socio-Cultural Advantages Of Federalism
}

\author{
Renebeth G. Donguiz \\ Benguet State University \\ Article History: Received: 11 January 2021; Accepted: 27 February 2021; Published online: 5 April 2021
}

\begin{abstract}
:
The government's ideal focus is to prioritize the citizenry's welfare when they intend to implement governance changes. This would include sustainable political, social, and economic development. In terms of political development, the officials must have a robust value system that motivates them to pursue equality, peace, justice, and overall development and implement policies against hostility and abuse. In terms of social development, the country must pursue the advancement of education, health, culture, information, and the environment. In terms of economic, the government must promote trade, employment, investment, infrastructure, technology, and inclusive growth. And Federalism is recently perceived in the Philippines as an ideal form of governance to eliminate dissidence in the country.

Federalism is being scrutinized in the Philippines since it has advantages, as observed among first-world countries like the USA, Australia, and Canada and developing countries like Mexico, India, and Brazil. Among these advantages include political advantages in which the regions or states could act independently in constitutionally drawn governance areas. Several social and economic drivers include technology, employment, and efficient use of resources pressing the government to change governance. These would require the regions or states to immediately cope with changes that confront them without relying on the government's bureaucratic system. In this manner, the government becomes closer to the constituents, allowing them to govern themselves, rule based on their own beliefs, culture, and joint problems, and pursue their advancement. For example, the states could issue licenses, provide for public health, conduct elections and form local governments, and look after intra-state trade (Tayeb, 2016).

This paper aims to measure the level of agreement of the constituents in the Cordillera Administrative Region (CAR) on the political, social, and economic advantages of Federalism. Moreover, this paper provides theoretical contributions on Federalism since there has been limited literature on Federalism in the Philippines. The study would also provide empirical evidence and findings on Federalism's advantages, particularly in the case of the Cordillera Administrative Region.
\end{abstract}

\section{THEORETICAL/ CONCEPTUAL FRAMEWORK}

The government must manifest justice, liberty, peace,, and accountability in all its agencie, particularly onxecutive, legislative, judiciary, and These were epitomized by the grand Greek philosophers Plato (c. 428-348 B.C.) and Aristotle (384-322 B.C.). They framed governance in the precepts of equality, justice, peace, and accountability. Plato, for instance, was adamant in his thought that the State shall promote morality, social harmony, good life, and the rule of law (Anerson \& Bowle, 2016). Aristotle also gave a view on justice by concluding that "it is evident that the form of government is best in which every man, whoever he is, can act best and live happily." Both Plato and Aristotle have been strong critiques of a tyrannical government. In a tyrannical government, the ruler becomes corrupt and uses his power to further his interests instead of working for the common good (Constitutional Rights Foundation-USA, 2016). Plato's realist assumption regards that most ordinary life is an illusion and current evils of politics due to the human pursuit of brute instinct (Anerson \& Bowle, 2016). Similarly, Aristotle expressed his disappointment for few responsible for decrees and authoritative laws and giving power to a few populaces having authority over everything. He firmly states that public power should promote16). 
In modern thought, Plato and Aristotle's philosophical thoughts should become underpinnings or pillars of any form of governance to realize its success. Nations must prevent tyranny and promote proper distribution and separation of powers, and these should be carefully observed to the equal branches of government: the executive, the legislative, and the judicial. Further, each branch can counter-check the other to prevent corruption or tyranny. The Constitution should also limit the government's powers by listing its powers, and the government may not exercise any power beyond those listed. Thus, in the proposed federal system, constitutional reforms should emulate the precepts of equality, justice, peace, and accountability. For instance, the equality could justify Federalism because it devolves power and recognizes the middle- and lower-class powers. Justice can also be advanced in the federal system because it can give equal opportunity for wealth, accommodates differences, and allows participation among the constituents. Peace can also be observed since the freedom and rights of persons are guaranteed. Lastly, accountability can also manifest since elected officials are responsible for their actions, and mechanisms for transparency will be available to citizens to have faith in their government.

Political Advantages of Federalism. Political advantages refer to the power arrangement and political participation of the people. In this sense, the federal government system should bring positive political changes making politicians more accountable for their actions, and leaders could perform check-and-balance. Federalism shall ratify existing structures that became a loophole used by opportunist individuals who are primarily enticed by personal interests. Constituents should also be observant of their politicians' actions, or else it may wreak havoc, and politicians may take advantage of the power given to them. Concerning this, Guillermo (2009) argued that Federalism should prove a better way of real institution reforms which shall be observed at the local level as well as the national level.

Generally, it has been believed that Federalism can provide several political advantages such a 1) federalism checks the growth of tyranny; 2) federalism allows unity without uniformity; 3) federalism encourages experimentation; 4) federalism keeps government closer to the people; 5) federalism allows for many political subcultures; 6) permits diversity and diffusion of power; 7) local governments can handle local problems better; 8) more access points for political participation; 9) protects individual rights against concentrated power; and 10) fosters experimentation and innovation (Walker, 1999).

Several works of literature also argue that Federalism has advantages. Accordingly, every Region has political, social, and economic problems peculiar to the Region itself. Citizens of various provinces may have different aspirations, ethnicity and follow different cultures. In this case, Federalism offers representation to different populations. The central government can sometimes overlook these differences and adopt policies that cater to the majority. This is where the regional government steps in. State governments have the freedom to adopt policies that may not be followed nationally or by any other state. The central government can concentrate more on international affairs and defense of the country while the provincial government can cater to the local needs. Federalism has room for experimentation. Two local governments can have different approaches to bringing reforms in any public domain area: taxation or education. The comparison of these policies' results can give a clear idea of which policy is better and can be adopted in the future (Walker, 1999).

Cognizant of several advantages of Federalism as experienced by countries, Watts (2008) has also presented merits of Federalism. The following are his concluding propositions on Federalism:

1.) Federal political systems provide a practical way of achieving through democratic representative institutions the management of multicultural conflict, but they are not a panacea for all such conflicts.

2.) The effective application of federal political solutions is limited to those situations where the necessary preconditions exist. Where these are lacking, a primary objective must be the establishment of processes to develop these preconditions.

3.) As a tool for the management of multicultural conflict, federal systems (both federations and confederations) have proved most effective as territorial political organizations. Therefore, their effective application is closely related to the degree to which different groups are territorially distributed or concentrated. 
4.) Federal arrangements are more likely to succeed where there are established traditions of democracy, constitutionalism, the rule of law, and political culture encouraging tolerance and compromise.

5.) Bicommunal institutional solutions tend to polarize and accentuate the conflict and suffer terminal instability, and therefore should be avoided.

6.) Where the institutional design of a federal system assures minorities of security for their distinctive self-governance, this has usually reduced tension and conflict.

7.) Institutional arrangements which involve genuine power-sharing within the federative institutions are essential in order to generate a continuing consensus which serves as the necessary glue to hold the federal system together.

8.) It must be emphasized that the application of federal solutions may take a variety of forms. There is no single universal form of federation applicable everywhere.

Abueva (2005) has also presented advantages of Federalism that can be viewed from a political perspective.

(1) The federal republic will build a just and enduring framework for peace through unity in our ethnic, religious, and cultural diversity. Federalism will accommodate legitimate interests and discourage secessionism.

(2) Decentralization and devolution cannot move further under the old unitary system despite avowed goals expressed in the 1987 Constitution and the Local Government Code. Federalism would be the logical and practical realization of the avowed decentralization and local autonomy issues that have been blocked by legislators who want to maintain their dominance over local leaders, governments, and communities.

(3) The Federal Republic will empower our citizens by enabling them to raise their standard of living and enhance their political awareness through their participation and efficacy in elections and the making and carrying out of government decisions at the regional and local levels. Governance will be improved, and corruption will be reduced by the new division of powers and functions between the Federal Government and the States and by the transparency of governance and its accessibility to the people in the regions, cities, provinces, and municipalities. It will bring a greater part of the government and decision-making closer to the people in the proposed States or regional governments and their cities and municipalities. With more power, authority, and resources managed by the leaders in the States and their local governments, which will be more visible and accessible to the people all over the country, the people will be more aware of the importance of electing good leaders. Corruption will be easier to detect and expose and punish.

(4) The Federal Republic will improve governance by challenging and energizing State and local leaders, entrepreneurs, and citizens around the country to take hold of their destiny. Federalism will release them from the costly, time-consuming, stifling, and demoralizing effects of excessive central government controls and regulation in our traditional Unitary System. It will encourage them to assume greater responsibility for leadership in making decisions and delivering services and for doing business. It will spur creativity and innovation, initiative and resourcefulness, and reduce local dependence on the national government. As the people will be more involved in government decisions, they will demand superior performance and public accountability of their political leaders and officials. At the same time, the people will be more willing to pay taxes that will finance government programs and services for their direct benefit.

(5) The Federal Republic will thus stimulate and hasten the country's political, economic, social, and cultural development. There will also be inter-State and regional competition in attracting domestic and foreign investments and industries, professionals and skilled workers, good teachers and scholars, artists, and tourists. A renaissance of regional languages, arts, and cultures will enrich the national language and culture and instill a deeper sense of both regional and national identities.

(6) Federalism, together with parliamentary government, will improve governance by promoting strong, united, disciplined, and program-oriented political parties responsible and accountable to the people for their conduct and performance in and out of power. 
(7) Gradually, the Federal Republic and its Parliamentary Government will broaden and deepen democracy. In the long run, it should enable the government, the political parties, the private sector, and the organizations and institutions of civil society to deliver on the constitutional promise of human rights, a better life for all, a just and humane society, and responsible and accountable political leadership and governance.

Social Advantages of Federalism. Social advantages refer to the accommodation of cultural differences, diversity of preferences, and identities. Citing the work of Rasul (2016), Federalism may not satisfy the separatists fighting for independence. Still, Federalism may address concerns of separatists who crave more autonomy, like in Muslim Mindanao. The peace pacts and proposed Bangsamoro Basic Law (BBL) are federalist powers. In this sense, autonomy and Federalism recognize the ethnic, linguistic, and religious differences and seek to make all communities an integral part of the whole nation (Rasul, 2016).

In addition, an annotated CMFP draft constitution, edited by the CMFP's advisory committee chairman, Abueva (2005) had provided advantages of Federalism:

(a) The Federal Republic will build a just and enduring framework for peace through unity in our ethnic, religious, and cultural diversity.

(b) Federalism will empower our citizens by enabling them to raise their standard of living and enhance their political awareness, participation, and efficacy in elections and the making of important government decisions. Governance will be improved, and corruption will be reduced. (c) Federalism will improve governance by empowering and challenging State and local leaders and entrepreneurs around the country....the people will be more willing to pay taxes to finance government programs and services for their direct benefit.

(d) Federalism will hasten the county's development....There will be inter-State and regional competition in attracting domestic and foreign investments and industries, professionals and skilled workers, good teachers and scholars, artists, and tourists. A renaissance of regional languages and cultures will enrich the national language and culture. The Federal Government will help support the less endowed and developed regions, and the poor and the needy across the land.

(e) Federalism, together with parliamentary government, will improve governance promoting the development of program-oriented political parties that are responsible and accountable to the people for their conduct and performance in and out of power.

(f) Federalism will broaden and deepen democracy and make its institutions deliver on the constitutional promise of human rights, a better life for all, a just and humane society, and responsible and accountable political leadership and governance (CMFP Draft Constitution February 2005:4-5).

Economic Advantages of Federalism. Economic advantages refer to the distribution of wealth and empowerment of local states along with their budget. Historically, there has been a worldwide interest that Federalism is probably a more robust governance system today. The benign concept of authoritarianism and aristocracy has been replaced by a self-rule governance system, coordinated national government, and diversity, creative experimentation, and liberty (Walker, 1999). Nowadays, the nation should look at the concept of an appropriate constituency. This is the suitability of a self-governing identity. The government needs to see and address diversity and think of the economic advantages of Federalism.

Several works of literature provided economic advantages of Federalism such as 1) devolves economic development plans that allow the federal states to be competitive on industries; 2) assumes more significant responsibility in making decisions and delivering services; 3) stimulates inter-State competition attracting domestic and foreign investments; 4) the more developed States will help support the less developed states; 5) distributes wealth across the country instead of the bulk going to the central government; 6) leaders and citizens level up in terms of quality of life, economic development, progressive policies, and governance; 7) greater empowerment to LGUs and have access to a bigger budget; 8) promotes budget autonomy to states; 9) provides adequate revenue to states; and 10) provide incentives to higher tax effort, and expenditure efficiency (Tanggol, 2012). 
The objective of the study

This paper aims to determine the constituents' level of agreement in the Cordillera Administrative Region on 1) the political advantages of Federalism, 2) the social advantages of Federalism, and 3) the economic advantages of Federalism. Further, it aims to assess whether there is a significant difference in the level of agreement of the constituents when they are grouped according to sex, age, line of work, dominant ethnic affiliation, and geographic domicile

\section{METHODOLOGY}

Design

The study employed a sequential explanatory research design. The descriptive survey method was used to measure the constituents of CAR's level of agreement on the political, social, and economic advantages of

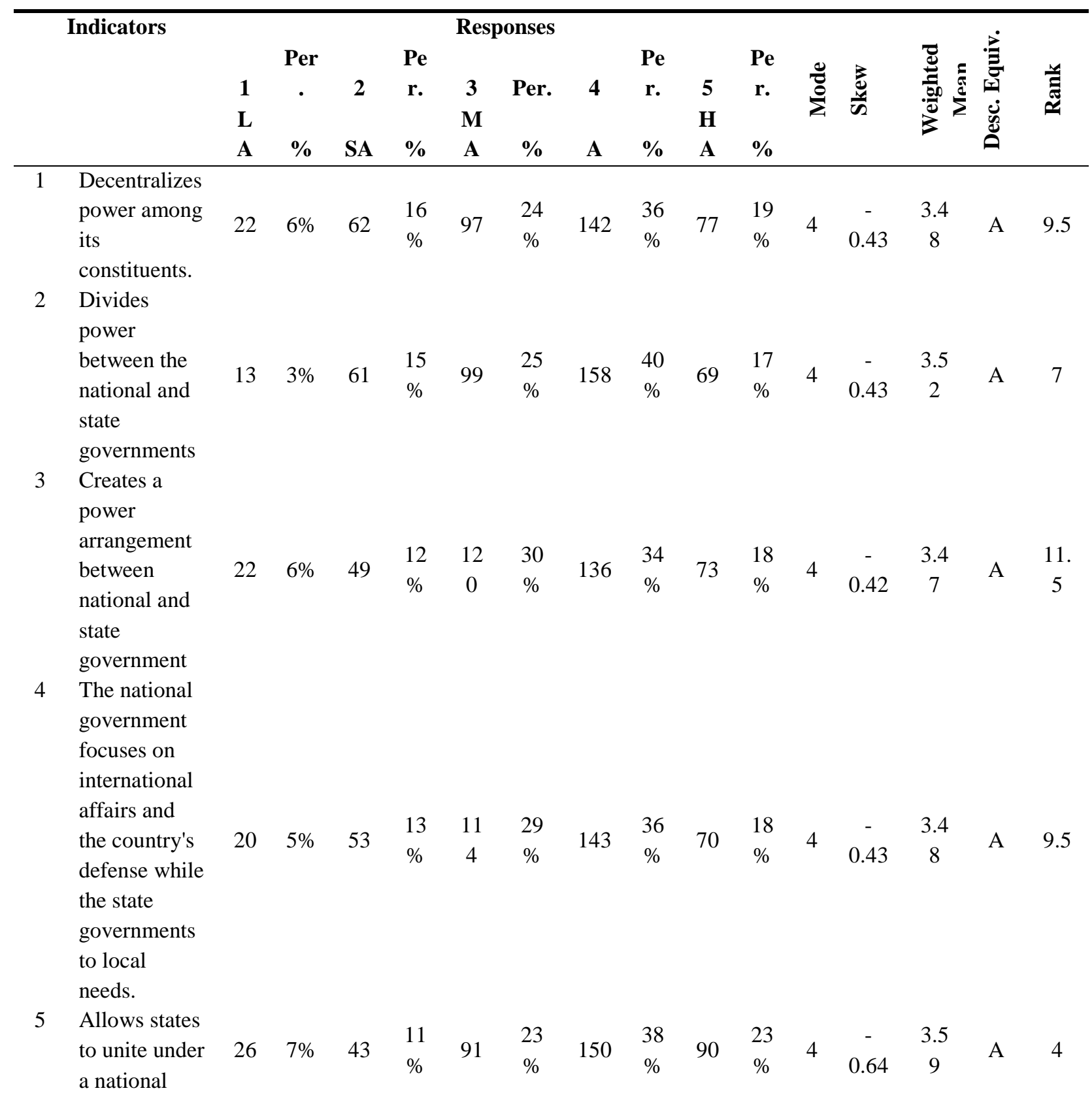


government

to maintain

independence

and

interdependen

ce.

6 Quicker

addressing, $\begin{array}{llllllllllllllll}\text { addressing, } \\ \text { debating, and } & 28 & 7 \% & 58 & 15 & 96 & 24 & 136 & 34 & 82 & 21 & 4 & - & 3.4 & \text { A } & 11 . \\ \text { ratifying of } & & & & \% & & \% & & \% & & \% & & 0.46 & 7 & & 5\end{array}$

the law.

7 Citizens and

elected

representative

s have more

power in

$\begin{array}{cccccc}20 & 5 \% & 56 & 14 & 10 & 27 \\ \% & 8 & \%\end{array}$

$133 \quad \begin{array}{cc}33 & 8 \\ \% & 8\end{array}$

21
$\%$

$\begin{array}{llcccc}4 & - & 3.5 & & & \\ & 0.41 & 1 & \text { A } & 8\end{array}$

public-

decision

making.

8 Avoids

corruption

because

power is not

centralized

into a single

$\begin{array}{lllll}27 & 7 \% & 48 & 12 & 93 \\ \% & 93 & \%\end{array}$

$\begin{array}{cccc}132 & 33 & 10 & 25 \\ \% & 0 & \%\end{array}$

$\begin{array}{ccc}4 & - & 3.5 \\ & 0.56 & 8\end{array}$

A 5

person or

group of

people.

9 Provides

framework

for creating

tailored law

in civic

participation,

$\begin{array}{cccccc}24 & 6 \% & 58 & 15 & 11 & 29 \\ \% & 4 & \%\end{array}$

31
$\%$

$82 \quad 21$

$\begin{array}{ccccc}1 & 4 & - & 3.4 & \mathrm{~A}\end{array}$

A 13

check against

centralized

power and

tyranny.

10 Encourage

political

change and

greater

$\begin{array}{llllll}17 & 4 \% & 45 & 11 & 95 & 24 \\ \% & & \%\end{array}$

140

advocacy

11 Brings power

closer to the

people that

leads to local

$\begin{array}{llllll}14 & 4 \% & 44 & 11 & & 22 \\ \% & 89 & \%\end{array}$

$143 \quad 36 \quad 11 \quad 28$

$\begin{array}{lcc}4 & - & 3.7 \\ & 0.62 & 3\end{array}$

A 1

government

participation

12 Provides

limitation of

political

$\begin{array}{llllll}20 & 5 \% & 53 & 13 & 95 & 24 \\ \% & & \end{array}$

$\begin{array}{cccc}118 & 30 & 11 & 29 \\ & \% & 4 & \%\end{array}$

$\begin{array}{ccc}4 & - & 3.6 \\ & 0.51 & 3\end{array}$

A 3

powers 
13 Encourages

political

participation

to influence

$\begin{array}{llll}18 & 5 \% & 60 & 15 \\ \%\end{array}$

99

25
$\%$

138

35
$\%$

85

$\begin{array}{ccccc}21 & & - & 3.5 & \\ \% & 4 & 0.43 & 3 & A\end{array}$

political

outcomes and

government

policy

\begin{tabular}{lrll}
\hline & 3.5 & \\
Overall Mean & 5 & Agree \\
Standard & 1.1 & \\
Deviation & 2 & \\
\hline
\end{tabular}

Federalism. Surveys were designed to gather information from samples using questionnaires or interviews (Campbell \& Stanley, 1963). The data collected were tabulated along with continuum form, described the events, and then organized, tabulates, depicts, and describes the data. The qualitative narratives gathered through key informant interviews were used to explain underlying reasons, opinions, and motivations to further the quantitative results.

Locale and Population of the Study

The study conducted a survey using a questionnaire that was administered to the targeted sample size of 400 composed of qualified electorates in CAR. From the sample size, there were 173 or $43.25 \%$ male and 227 or $56.75 \%$ female. When they are grouped according to age, there were 52 or $13 \%$ with age $18-20,77$ or $19.25 \%$ with age $21-30,236$ or $59 \%$ with age $31-65$, and 32 or $8 \%$ with age 66 and above. When they are grouped according to a line of work, there are 80 or $20 \%$ from the agriculture, 3 or $.75 \%$ are appointed official, 56 or $14 \%$ businessman/woman, 19 or $4.75 \%$ from the financial institution, 7 or $1.75 \%$ from fishery, 49 or $12.25 \%$ government employee, 13 or $3.25 \%$ from tourism, 24 or $6 \%$ from the non-government organization, 4 or $1 \%$ from media, 10 or $2.50 \%$ are elected officials, 20 or $5 \%$ from the academe, 30 or $7.50 \%$ are students, 6 or $1.50 \%$ are lawyers, and 38 or 9.50 are private employees. When they are grouped by dominant ethnic affiliation, 18 or $4.50 \%$ are Kalanguya, 98 or $24.50 \%$ are Kankanaey, 32 or $8 \%$ are Ibontoc, 48 or $12 \%$ are Ifugao, 76 or $19 \%$ are Ilocano, and 42 or $10.50 \%$ are Isnag. When they are grouped according to geographic domicile, there are 53 or $13.25 \%$ are from Abra, 50 or $12.50 \%$ are from Apayao, 67 or $16.75 \%$ are from Benguet, 67 or $16.75 \%$ are from Baguio City, 50 or $12.50 \%$ are from Ifugao, 53 or $13.25 \%$ are from Kalinga, and 60 or $15 \%$ are from Mountain Province.

Data Gathering Tool

The research made use of a survey questionnaire that was drafted based on gathered literature from reliable references. Further, key informant interviews were conducted to gather relevant information, explanations, and several perspectives.

Validity and Reliability of the Instrument

For content validity, several professors and public administrators validated the questionnaire. Their comments and suggestions were considered in the questionnaire. Further, Aiken's V Coefficient computed validity index which is 0.94 indicates that the questionnaire is valid. The questionnaire was also pre-tested among forty (40) tourists in Baguio City based on random pre-testing. The reliability coefficient based on Cronbach's alpha of 0.94 indicates excellent reliability.

Statistical Treatment of the Data

The data was measured based on a 5-point Likert Scale. '5' indicates a high level of agreement (HA), '4' indicates agreement (A), '3' indicates moderate agreement (MA), '2' indicates slight agreement (SA), and ' 1 ' indicates a low level of agreement (LA). The answers were treated using mode, skewness, weighted mean, standard deviation, and rank. To compare the weighted means and determine significant differences, the Analysis of Variance (Anova) was used. 


\section{RESULTS AND DISCUSSIONS}

The overall result presents that the constituents in CAR agree on the political advantages of Federalism with an overall mean of $3.55(\sigma=1.12)$, social advantages of Federalism with an overall mean of $3.61(\sigma=1.09)$, and economic advantages of Federalism with an overall mean of $3.64(\sigma=1.10)$.

Table 1. presents the level of agreement of the constituents in CAR on the political advantages of Federalism.

Table 1. Level of Agreement on the Political Advantages of Federalism

The overall result indicates that the constituents in CAR agree to the political advantages of Federalism as indicated by the overall mean of $3.55(\sigma=1.16)$ and all of the indicators has a mode of 4 , and their responses were negatively skewed (L), which means that most of the responses were falling towards higher responses and few have low responses. This means that the constituents in CAR agree that Federalism could bring favorable political reforms, which may bring political advantages. The result was supported by one of the interviewed congressman stating that "federalism is advantageous because powers will be distributed among states and they have the power to manage their resources and decide for themselves what will work best for the people... as compared to a unitary system that relies on the bureaucratic system." Moreover, the result was supported by another interviewed local official stating that "I was able to observe in the recently held forum in Davao. They discussed that all levels of government would be empowered until the Barangay level...it was a very good governance structure." Additionally, an interviewed chairman of a united states that "federalism is preferable because the local government has specific power and sphere of influence."

The highest agreed indicator is "brings power closer to the people that lead to local government participation." The result may indicate that the constituents agree that Federalism would allow them to participate in their local government, enabling them to voice their concerns and issues to the government. This was supported by one of the interviewed local officials. They stated that Federalism is better than unitary or autonomy because, in these forms of governance, power is retained by few officials. If federal will be implemented, the President will just be the figurehead, the prime minister will be the executive, and the states can run their affairs based on the will of the populace in the states." Moreover, the result affirms what Lagdameo (2009) has pointed out that Federalism allows local states to draw up their constitutions, and the people are given authority to govern their lives according to the social contract they enter into with each other.

The lowest observed indicator is "provides a framework for creating tailored law in civic participation, check against centralized power and tyranny." The result presents that the constituents agree on the indicator. Still, the constituents could probably need to assess the frameworks that are needed to be implemented to ensure civic participation and check against centralized power and tyranny. The result is supported and explained by one of the interviewed congressmen who stated that "some worry about the possibility that CAR will not be properly represented but for sure there will be equal representation. The senator who will be elected will represent the entire State. The federal system will be discussed in Congress but definitely, it will be through a Constituent Assembly. The President will then appoint to know the sentiments of the people and draft the Constitution. Afterward, the Constituent Assembly will form committees to ratify the draft." As it manifested in the interview, there were no clear provisions regarding governance frameworks; thus, the constituents in CAR may not fully agree that Federalism would provide the framework for checking against centralized power and tyranny.

Table 2 presents the level of agreement of the constituents in CAR on the social advantages of Federalism.

Table 2. Level of Agreement on the Social Advantages of Federalism

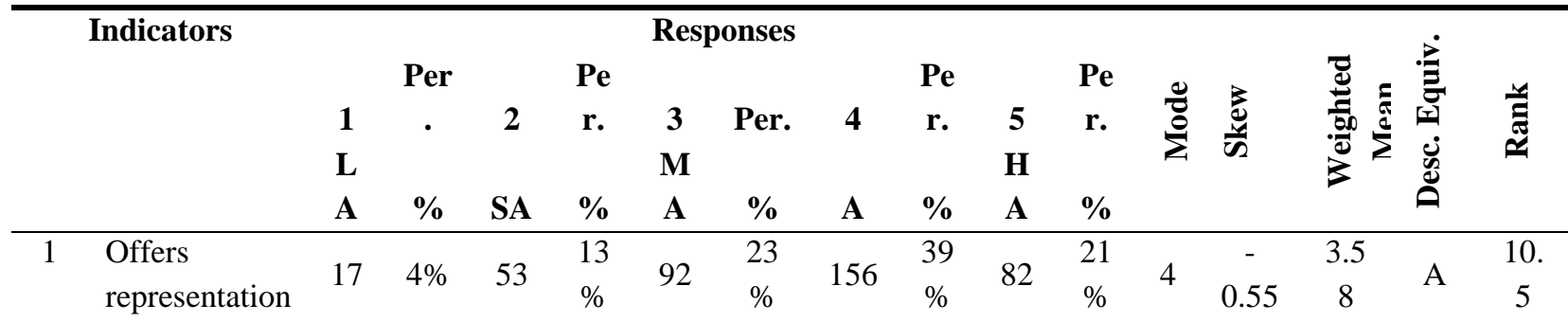


of different

populations

2 Protects the rights of the minorities

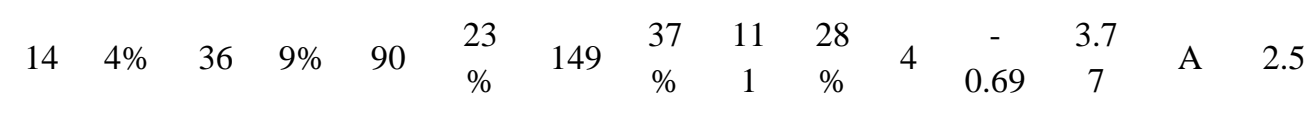

3 Allows local governments

to enact

policies

involving

$\begin{array}{llllll}11 & 3 \% & 39 & 10 & 96 & 24 \\ \% & 96 & \end{array}$

$140 \quad 35$

$\begin{array}{llllcc}35 & 11 & 29 & 4 & - & 3.7 \\ \% & 4 & \% & 4 & 0.59 & 7\end{array}$

A $\quad 2.5$

moral and

social issues.

4 States devise

their own

solutions

based on their

situation,

culture,

geography,

aspirations,

preferences,

peculiarities,

social and

economic

context.

5 Builds a just

and

framework

for peace

through unity

$\begin{array}{llllll}10 & 3 \% & 49 & 12 & 76 & 19 \\ \% & 7\end{array}$

$149 \begin{array}{ccc}37 & 11 & 29 \\ \% & 6 & \%\end{array}$

$\begin{array}{cc}- & 3.7 \\ 0.64 & 8\end{array}$

A 1

in ethnic,

religious, and

cultural

diversity.

6 Instils deeper sense of both regional and national

$\begin{array}{ccccccccccccccc}16 & 4 \% & 48 & 12 & 10 & 26 & 140 & 35 & 91 & 23 & 4 & - & 3.6 & \text { A } & 8.5\end{array}$ identities

7 Accommodat es legitimate interests that would discourage $\begin{array}{llllll}23 & 6 \% & 58 & 15 & 92 & 23 \\ \% & 92 & \%\end{array}$

$\begin{array}{cccccccc}134 & 34 & 93 & 23 & & - & 3.5 & \mathrm{~A}\end{array}$

war,

rebellion, and

secessionism.

8 Addresses

concerns of separatists

who crave for

$27 \quad 7 \% \quad 58 \quad \begin{array}{llll}15 & 10 & 26 \\ & \% & 3 & \%\end{array}$

$137 \quad \begin{array}{ll}34 & 75\end{array}$

19

$\begin{array}{cccc}4 & - & 3.4 \\ 0.43 & 4 & \mathrm{~A}\end{array}$

autonomy. 
9 Conducive to

greater

freedom of

choice,

diversity of

preference,

$\begin{array}{llllll}18 & 5 \% & 41 & 10 & 99 & 25 \\ & & & \% & & \%\end{array}$

38
$\quad \%$

89

$\begin{array}{llcc}22 & & - & 3.6 \\ \% & 4 & 0.61 & 4\end{array}$

A 6

innovation,

accountability

, social taste

and attitude.

10 People are

active

participants

$\begin{array}{cccccc}21 & 5 \% & 51 & 13 & 11 & 28 \\ \% & 1 & \%\end{array}$

123

$\begin{array}{llllccc}31 & 94 & 24 & & - & 3.5 & \\ \% & & \% & & 0.43 & 5 & \text { A }\end{array}$

12

than passive

recipients.

11 Promotes

empowermen

$\mathrm{t}$ of citizens

and closer

$\begin{array}{cccccc}25 & 6 \% & 38 & 10 & 10 & 27 \\ \% & 9 & \%\end{array}$

136

$\begin{array}{ll}34 & 92\end{array}$

$\begin{array}{cccc}23 & & - & 3.5 \\ \% & 4 & 0.57 & 8\end{array}$

A $\quad 10$

collaboration

with

stakeholders.

12 Provides

environmenta

1

competitivene

$\begin{array}{llllll}13 & 3 \% & 46 & 12 & 93 & 23 \\ \% & 93\end{array}$

$144 \begin{array}{ccc}36 & 10 & 26 \\ \% & 4 & \%\end{array}$

$\begin{array}{cc}- & 3.7 \\ 0.57 & 0\end{array}$

A 5

ss and

sustainability.

13 Provides

management

of multi-

$19 \quad 5 \%$

43

$\begin{array}{ccc}11 & 11 & 28 \\ \% & 1 & \%\end{array}$

$130 \quad 33$

33
$\%$

97

24
$\%$

$\begin{array}{cc}- & 3.6 \\ 0.50 & 1\end{array}$

A

conflict

14 Reduces

ethnic

tensions and

$\begin{array}{cccccc}21 & 5 \% & 44 & 11 & 10 & 27 \\ & & & 6 & 6 & \%\end{array}$

121

$\begin{array}{cc}30 & 10 \\ \% & 8\end{array}$

27
$\%$

$\begin{array}{ccc}4 & - & 3.6 \\ & 0.52 & 3\end{array}$

A 7

conflict

Overall Mean

4 Agree

1.1

Standard Deviation

0

The overall result indicates that the constituents in CAR agree to the social advantages of Federalism as indicated by the overall mean of $3.64(\sigma=1.10)$ and all of the indicators has a mode of 4 , and their responses were negatively skewed (L), which means that most of the responses were falling towards higher responses and few have low responses. The result indicates that the constituents in CAR agreeFederalism could bring favorable impact on the social aspect of the country. The result was supported by one interviewed congressman who stated that "ethnicity will still be promoted and convergence of regions is still favorable. People with similar ethnicity or culture are still represented. Even CAR, Region I, Region II will converge for synergy. I prefer CAR converged with Region I and Region II because it will be a synergy. Each of the regions can benefit from each other's resources." The result of the interview clarifies that whether CAR will be converged Region I and Region II, the constituents' culture will still be promoted. Moreover, the converged regions can benefit from each other's 
resources that may allow them to devise better solutions based on their situations, culture, geographic, aspirations, preferences, peculiarities, the social and economic context, which affirms what Rasul (2016) had pointed out.

The highest indicator agreed upon by the CAR constituents is "builds a just and framework for peace through unity in ethnic, religious and cultural diversity". The result indicates that the constituents in CAR perceived that through Federalism, they can pursue peace through unity in ethnic, religious, and cultural diversity. According to one of the interviewed local official, he states that "federalism and autonomy are similar since both of them pursue the ethnic, religious and cultural aspirations of CAR...either federalism or autonomy could be pursued...but since federalism is already an agenda of President Duterte, our desire for autonomy is already finished when federalism is implemented" The result of the interview presents that the desires of the proponents for autonomy could already be answered Federalism since states or regions could govern themselves by considering their ethnic, religious, and cultural diversity. The result also affirms what Abueva (2005) has pointed out that Federalism will build a just and enduring framework for peace through unity in our ethnic, religious, and cultural diversity. In this manner, Federalism could accommodate legitimate interests and discourage secessionism.

The lowest observed indicator is "addresses concerns of separatists who crave for autonomy," where the constituents agree. Still, they may not fully agree that it would primarily address the separatist's concerns who crave autonomy. Historically, the move for autonomy failed during the past two plebiscites because several constituents could assess that autonomy was self-serving to some few politicians. In general, the constituents aspire for genuine autonomy. Several observed constituents are interested in Federalism because it could bring them genuine autonomy in which the governance structure is already built in a manner they could participate. In this sense, Federalism may not primarily address the separatist's concerns who craves autonomy, but constituents may support Federalism because it may resolve several social issues. The result was supported by one elected official who stated that "federalism is more preferred than autonomy because it can distribute power among the levels of government allowing them to address the concerns of the citizens...however in autonomy, power is retained by few officials - the same politicians."

Table 3 presents the level of agreement of the constituents in CAR on the economic advantages of Federalism.

Table 3. Level of Agreement on the Economic Advantages of Federalism

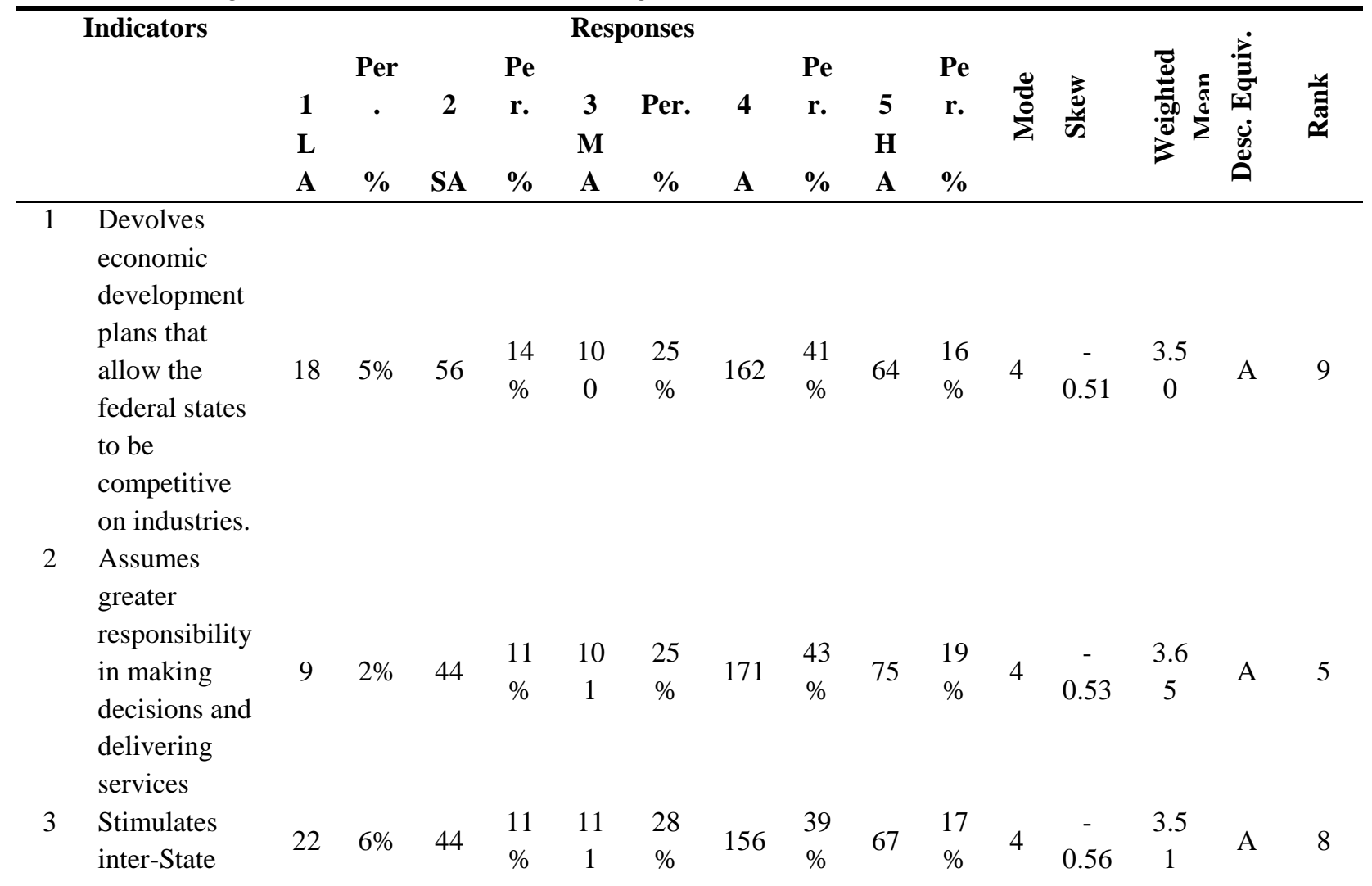


competition

attracting

domestic and

foreign

investments

4 The more

developed

States will

help support

$\begin{array}{cccccc}25 & 6 \% & 44 & 11 & 10 & 27\end{array}$

$142 \quad 36$

the less

developed

states

5 Distributes

wealth across

the country

instead of the

$\begin{array}{llllll}18 & 5 \% & 43 & 11 & 77 & 19\end{array}$

19
$\%$

$\begin{array}{cccc}154 & 39 & 10 & 27 \\ \% & 8 & \%\end{array}$

bulk going to

the central

government.

6 Leaders and

citizens level

up in terms of

quality of

life,

economic

$\begin{array}{llllll}11 & 3 \% & 52 & 13 & 10 & 25 \\ \% & 0 & 9\end{array}$

$\begin{array}{cccc}128 & 32 & 10 & 27 \\ & \% & 9 & \%\end{array}$

$\begin{array}{ccc}4 & - & 3.6 \\ & 0.46 & 8\end{array}$

A 3

development,

progressive

policies, and

governance.

7 Greater

empowermen

$\mathrm{t}$ to LGUs

and have

access to a

$\begin{array}{cccccc}12 & 3 \% & 44 & 11 & 10 & 25 \\ \% & 1 & \%\end{array}$

151

$\begin{array}{cccccc}38 & 92 & 23 & 4 & - & 3.6 \\ \% & 92 & \% & & 0.53 & 7\end{array}$

A 4

bigger

budget.

8 Promotes

budget

autonomy to

$\begin{array}{llllll}12 & 3 \% & 42 & 11 & 97 & 24 \\ \% & & & \%\end{array}$

$135 \begin{array}{cccc}34 & 11 & 29 \\ \% & 4 & \%\end{array}$

$\begin{array}{ccc}4 & - & 3.7 \\ & 0.57 & 4\end{array}$

A 1

states

9 Provides

adequate

revenue to

$15 \quad 4 \%$

60

15
$\%$

$89 \quad \begin{aligned} & 22 \\ & \%\end{aligned}$

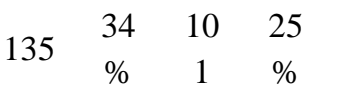

$\begin{array}{ccc}4 & - & 3.6 \\ & 0.47 & 2\end{array}$

A 6

states

10 Provide

incentives to

higher tax

effort, and

$\begin{array}{cccccc}28 & 7 \% & 55 & 14 & 11 & 29 \\ & & & \% & 7 & \%\end{array}$

108

27
$\%$

92

23
$\%$

$\begin{array}{ccc}3 & - & 3.4 \\ & 0.35 & 5\end{array}$

A 10

expenditure

efficiency.

Overall Mean

1 Agree 
The overall result indicates that the constituents in CAR agree to the economic advantages of Federalism as indicated by the overall mean of $3.61(\sigma=1.09)$ and most of the indicators have a mode of 4 , and their responses were negatively skewed (L), which means that most of the responses were falling towards higher responses and few have low responses. The result indicates that Federalism could bring economic advantages among states, allowing them to prosper since the states can manage their own affairs without relying heavily on the central government. The result was supported by one of the interviewed congressman stating that Federalism...will benefit the Region. Under the federal system, revenues collected within the State will be for infrastructure and regional development thus, infrastructure and benefits will accrue the area." Moreover, one of the interviewed federation presidents emphasized that "under Federalism, revenue and taxation is adjusted. The localities benefit from the revenues and taxes they collect as compare to the current centralized government wherein the people may not directly benefit from their income because it would always depend on the national level." The result of the interviews clarifies that the regions will benefit directly from the tax revenues they collect. In this manner, the regions could improve their economy and create employment, trade, infrastructure, etc., for them to benefit their constituents.

The highest observed agreed upon indicator is "promotes budget autonomy." This indicates that the constituents agree that budget autonomy would bring economic advantages. ThroughFederalism, the states can identify their unique needs, and they can allot their collected revenues to fund these needs. The result affirms one interviewed congressman who stated that "under a federal system, revenues collected within the State will be for infrastructure and regional development. Thus the infrastructure and benefits will accrue to the area." Moreover, one interviewed elected official also stated that "budget autonomy will provide better job opportunity within the region and revenues could be used for development."

The lowest observed indicator is "provides incentives to higher tax effort and expenditure efficiency". The result indicates that most constituents do not fully agree that Federalism could provide incentives to higher tax effort and expenditure efficiency. Among the respondents, it was observed that some of them suspect that Federalism could lead to complicated taxation in which there will be separate national and local taxes which can become burdensome to the constituents. Moreover, one interviewed congressman stated that "when CAR would be a separate state, a thorough study needs to be conducted if the resources of CAR can sustain itself. UnderFederalism, Internal Revenue Allotment (IRA) will not be provided anymore by the national government. Thus, the State would have to sustain its own needs." The result of the interview could imply that for the State or province to sustain itself, taxation can be an issue since the local State must sustain itself. To sustain the needs of the State, tax adjustments could be necessary to fund the expenditures of the State or Region.

Table 4 presents the variance analysis on the significant differences in the level of agreement of the constituents in CAR on the political, social, and economic advantages when they are grouped according to sex, age, line of work, ethnic affiliation, and geographic domicile.

Table 4. Analysis of Variance Results on the Level of Awareness on the Nature, Structure and Processes of Federalism

\begin{tabular}{|c|c|c|c|c|c|}
\hline Problems 1, 2 and 3 & Sex & Age & Line of Work & $\begin{array}{l}\text { Ethnic } \\
\text { Affiliation }\end{array}$ & $\begin{array}{l}\text { Geographic } \\
\text { Domicile }\end{array}$ \\
\hline \multirow[t]{3}{*}{ Political advantages } & $F=46.9041$ & $\mathrm{~F}=571.792$ & $\mathrm{~F}=12.3803$ & $\mathrm{~F}=48.5831$ & $\mathrm{~F}=85.4944$ \\
\hline & Significant & Significant & Significant & Significant & Significant \\
\hline & Reject $\mathrm{H}_{\mathrm{o}}$ & Reject $\mathrm{H}_{\mathrm{o}}$ & Reject $\mathrm{H}_{\mathrm{o}}$ & Reject $\mathrm{H}_{\mathrm{o}}$ & Reject $\mathrm{H}_{\mathrm{o}}$ \\
\hline \multirow[t]{3}{*}{ Social Advantages } & $\mathrm{F}=10.7587$ & $F=86.9907$ & $F=14.6725$ & $\mathrm{~F}=36.8910$ & $\mathrm{~F}=58.7490$ \\
\hline & Significant & Significant & Significant & Significant & Significant \\
\hline & Reject $\mathrm{H}_{\mathrm{o}}$ & Reject $\mathrm{H}_{\mathrm{o}}$ & Reject $\mathrm{H}_{\mathrm{o}}$ & Reject $\mathrm{H}_{\mathrm{o}}$ & Reject $\mathrm{H}_{\mathrm{o}}$ \\
\hline
\end{tabular}




$\begin{array}{llllll}\text { Economic } & \mathrm{F}=60.12922 & \mathrm{~F}=674.171 & \mathrm{~F}=15.03426 & \mathrm{~F}=30.2706 & \mathrm{~F}=71.8264 \\ \text { Advantages } & \text { Significant } & \text { Significant } & \text { Significant } & \text { Significant } & \text { Significant } \\ & \text { Reject Ho } & \text { Reject Ho } & \text { Reject Ho } & \text { Reject Ho } & \text { Reject Ho }\end{array}$

The result of the analysis of variance (ANOVA) presents significant differences along with the moderating variables such as sex, age, line of work, ethnic affiliations, and geographic domicile, which indicates that they have varying responses and level of awareness on the political, social and economic advantages of Federalism. The constituents may have a varying assessment of Federalism's advantages, and they may not have a common level of agreement on the political, social, and economic advantages. The result presents that their personal attributes such as sex, age, line of work, ethnic affiliations, and geographic domiciles are relevant factors that could affect their level of agreement. The study supports some empirical findings that personal attributes are factors that contribute to an individual's perception. For instance, Campbell (2016) empirically found evidence that there is a gender gap in political attitudes between men and women. Ferris, Adams, Hochwarter, and Ammeter (2002) also positioned that age is an antecedent of political perceptions. Robbins, Millet, and Waters-Marsh (2004) also stated that a person's work environment and reality might give meaning to their environment, including the political environment. Jenkins (200) also argued that culture and ethnic identity have become a legitimate political basis of individual and collective choice affected by their genetic potential and born into a social and cultural setting like family, community, social class, language, and religion. Lastly, Memon and Sami (2012) found that geographic domicile played a significant role in the political perception and reorganization process.

\section{CONCLUSION}

This study suggests a thorough evaluation of any political reforms if they would bring political, social, and economic advantages before they would be implemented. In this way, this study determined the level of agreement of the constituents in CAR on the political, social, and economic advantages of Federalism. The research reveals that the constituents in CAR agree to the political, social, and economic advantages. However, they may have varying responses when they are grouped according to sex, age, line of work, ethnic affiliations, and geographic domicile. In general, the constituents agree that Federalism would bring power closer, allowing Federalism to build a framework of justice and peace through unity in ethnic, religious, and cultural diversity. Federalism would also allow states to manage their revenue by promoting budget autonomy. On the other hand, constituents may not fully agree that Federalism would provide a governance framework that tailors participation and checks against centralized power and tyranny. Federalism may not also fully address the concerns of the separatists who crave autonomy. Lastly, Federalism may not fully provide incentives to higher tax effort and expenditure efficiency. This research gives an implication to policymakers that they should polish and improve those identified areas that need to be addressed.

\section{RECOMMENDATIONS}

In light of the findings and conclusions of the Study, the following recommendations are hereby proposed.

1. The policymakers of Federalism must provide a concrete framework for creating laws that were tailored in civic participation to allow checking against centralized power and tyranny. For instance, Congress must draft Constitution that empowers the citizens to reject centralized power or tyranny and also provide them a framework for equal representation and civic participation in their local states.

2. There must be a public hearing and consultation to address the concerns of separatists who crave autonomy so that their concerns will be integrated with the federal system to prevent future dissidence and conflicts with the national government or with other states.

3. Federalism policymakers must design an appropriate fiscal policy to avoid complicated taxation and ensure expenditure efficiency of the local states. 


\section{REFERENCES}

1. Abueva, J. (2005). Some Advantages of Federalism and Parliamentary Government for the Philippines. Retrieved from http://pcij.org/blog/wp-docs/Abueva-Federalism.pdf

2. Anerson, J. and Bowle, J. (2016).Political Philososphy. Encyclopedia Britannica. Retrieved from https://www.britannica.com/topic/political-philosophy

3. Campbell, D. and Stanley, J. (1963). Experimental and Quasi-Experimental Designs for Research. USA: Houghton Mifflin Company

4. Campbell, R. (2016). Representing Women Voters: The Role of the Gender Gap and the Response of Political Parties. Sage Journals, 22 (5), 587-597

5. Constitutional Rights Foundation-USA (2016). Plato and Aristotle on Tyranny and the Rule of Law. Retrieved from http://www.crf-usa.org/bill-of-rights-in-action/bria-26-1-plato-and-aristotle-on-tyrannyand-the-rule-of-law.html

6. Ferris, G. R., Adams, G. Koldinsky, R. Hochwarter, W. and Ammeter (2002). Perceptions of organizational politics: Theory and research directions. In F. J. Yammarino \& F. Dasenreau (ed.) (pp. 179-254). The many faces of multi-level issues (Research in Multi Level Issues, Volume 1). Emerald Group Publishing Limited.

7. Guillermo, M. (2009). Decentralization Modalities in Framing a Federal Constitution. In K. Preschle \& E. Tayao, Envisioning a Federal Philippines (pp. 36-50). Manila, Philippines: The Local Government Development Foundation (LOGODEF).

8. Jenkins, R. (2000). The Limits of Identity: Ethnicity, Conflict, and Politics. Sheffield Online Papers in Social Research. Retrieved from https://www.sheffield.ac.uk/polopoly_fs/1.71447!/file/2jenkins.pdf

9. Lagdameo, A. J. (2009). How to Structure Federalism in the Philippines. In K. Preschle \& E. Tayao, Envisioning a Federal Philippines (pp. 14-35). Manila, Philippines: The Local Government Development Foundation (LOGODEF).

10. Memon, A. and Sami, K. Prerequisites ofFederalism: a case of Pakistan. Sindh University Journals Online, 30-37.

11. Rasul, A. (2016, October 21). Autonomy and Federalism. Retrieved from http://www.bworldonline.com/content.php?section=Opinion\&title=autonomy-andfederalism\&id=135212

12. Robbins, S. Millet, B. and Waters-Marsh, T. (2004). Organisational behaviour. South Melbourne, VIC, Australia: Pearson Australia

13. Tanggol, S. (2012). Regional Autonomy and Federalism: Concepts and Issues for the Bangsamoro Government. Philippines: MSU-Iligan Institute of Technology

14. Tayeb, M. (2016). Advantages and Disadvantages of Federalism. Scribd. Retrieved from the website of Scribd: https://www.scribd.com/doc/24350375/Advantages-and-Disadvantages-of-Federalism

15. Walker, G. Q. (1999).Ten Advantages of a Federal Constitution. Australian Law Journal, 73 (9), 634 58.

16. Watts, R. (1998). Federal Systems and Accommodation of Distinct Groups: A Comparative Survey of Institutional Arrangements for Aboriginal Peoples. Kingston, Ontario: Institute of Intergovernmental Relations, Queen's University. 